\title{
Immunotherapy of Peritoneal Carcinomatosis with the Antibody Catumaxomab in Colon, Gastric, or Pancreatic Cancer: An Open-Label, Multicenter, Phase I/II Trial
}

\author{
Michael A. Ströhlein ${ }^{a} \quad$ Florian Lordick $^{b}$ Dominik Rüttinger ${ }^{c} \quad$ Klaus-Uwe Grützner $^{a}$ \\ Oliver C. Schemanski ${ }^{a} \quad$ Michael Jäger $^{d}$ Horst Lindhofer $^{e} \quad$ Michael Hennig $^{f}$ \\ Karl-Walter Jauch ${ }^{c}$ Christian Peschel ${ }^{g}$ Markus M. Heiss ${ }^{a}$
}

\author{
aDepartment of Abdominal, Vascular and Transplant Surgery, Cologne Merheim Medical Center, University of Witten-Herdecke, Cologne, \\ ${ }^{b}$ Department of Medical Oncology, National Center for Tumor Disease, University of Heidelberg, \\ 'Department of Surgery, Klinikum Großhadern, Ludwig Maximilians University Munich, \\ ${ }^{\mathrm{d}}$ TRION Research GmbH, Martinsried, \\ 'TRION Pharma GmbH, \\ fFresenius Biotech $\mathrm{GmbH}$, Munich, \\ ${ }^{9}$ Department of Hematology and Medical Oncology, Klinikum rechts der Isar, Technical University Munich, Germany
}

\section{Keywords}

Epithelial cell adhesion molecule (EpCAM) .

Catumaxomab · Antibody, trifunctional · Immunotherapy ·

Peritoneal carcinomatosis

\section{Summary}

Background: Peritoneal carcinomatosis (PC) is common in gastrointestinal (GI) cancer and there is no effective standard treatment. We investigated the tolerability and maximum tolerated dose (MTD) of the trifunctional antibody catumaxomab in patients with PC. Methods: In this openlabel, phase $\mathrm{I} / \mathrm{Il}$ clinical trial, patients with epithelial cell adhesion molecule (EpCAM)-positive PC from GI cancer received 4 sequential intraperitoneal catumaxomab infusions: day 0: $10 \mu \mathrm{g}$; day 3: 10 or $20 \mu \mathrm{g}$; day 7:30,50, or $100 \mu \mathrm{g}$; and day 10: 50,100 , or $200 \mu \mathrm{g}$. Dose escalation was guided by dose-limiting toxicities. Results: The MTD was 10, 20, 50, and $200 \mu \mathrm{g}$ on days $0,3,7$, and 10, respectively. Catumaxomab had an acceptable safety profile: Most common treatment-related adverse events (at the MTD) were fever, vomiting, and abdominal pain. At final examination, 11/17 evaluable patients $(65 \%)$ were progression free: 1 patient had a complete and 3 a partial response. Median overall survival from the time of diagnosis of PC was 502 days. Conclusions: Intraperitoneal catumaxomab is a promising option for the treatment of PC from GI cancer.

\author{
Schlüsselwörter \\ Epitheliales Zell-Adhäsionsmolekül (EpCAM) . \\ Catumaxomab · Antikörper, trifunktionaler . \\ Immuntherapie $\cdot$ Peritonealkarzinose
}

\section{Zusammenfassung}

Hintergrund: Die Peritoealkarzinose (PC) ist eine häufige, schwerwiegende Folge von gastrointestinalen (GI) Tumoren, für die derzeit keine wirkungsvolle Standardtherapie existiert. Dieser Beitrag beschreibt die Verträglichkeit und Maximaldosis (MTD) des trifunktionalen Antikörpers Catumaxomab bei Patienten mit PC. Methoden: In dieser offenen Phase-I/II-Studie erhielten Patienten mit EpCAM (epitheliales Zell-Adhäsionsmolekül)-positiver PC aufgrund eines Gl-Tumors 4 sequenzielle Infusionen Catumaxomab intraperitoneal: Tag 0: $10 \mu$ g; Tag 3: 10 oder $20 \mu$; Tag 7: 30, 50 oder $100 \mu \mathrm{g}$; Tag 10: 50, 100 oder $200 \mu \mathrm{g}$. Die Dosissteigerung richtete sich nach den dosislimitierenden Toxizitäten. Ergebnisse: Die MTD wurde bei 10, 20, 50 und $200 \mu \mathrm{g}$ entsprechend an den Tagen 0, 3, 7 und 10 bestimmt. Catumaxomab zeigte ein akzeptables Sicherheitsprofil: Die meisten behandlungsbedingten Nebenwirkungen (bei Erreichen der MTD) waren Fieber, Übelkeit und abdominale Schmerzen. 11 von 17 auswertbaren Patienten waren zum Zeitpunkt der finalen Auswertung progressionsfrei: 1 Patient hatte eine komplette, 3 eine partielle Remission. Das mediane Gesamtüberleben seit PC-Diagnosestellung lag bei 502 Tagen bei Patienten mit Catumaxomab-Therapie. Schlussfolgerungen: Die intraperitoneale Catumaxomab-Therapie ist eine vielversprechende Therapieoption bei PC aufgrund von GITumoren.

\section{KARGER \\ Fax +497614520714 \\ Information@Karger.de}

www.karger.com (c) 2011 S. Karger GmbH, Freiburg 0378-584X/11/0343-0101\$38.00/0

Accessible online at: www.karger.com/onk
Prof. Dr. med. Markus M. Heiss

Department of Abdominal Vascular and Transplant Surgery

Cologne Merheim Medical Center, University of Witten-Herdecke

Ostmerheimer Straße 200, 51109 Cologne, Germany

Tel. +49 221 8907-3770, Fax -8561

heissm@kliniken-koeln.de 


\section{Introduction}

Peritoneal carcinomatosis (PC) is a common event in patients with gastrointestinal (GI) cancer and is associated with poor survival and deteriorating quality of life [1-3]. Systemic chemotherapy has shown minimal efficacy [4, 5]. Only selected patients with small-volume PC benefit from peritonectomy plus intraoperative intraperitoneal chemotherapy $[6,7]$. Currently, there is no effective treatment for the majority of patients with advanced PC.

Catumaxomab (anti-EpCAM $\times$ anti-CD3) $\left(\right.$ Removab $^{\circledR}$, Fresenius Biotech $\mathrm{GmbH}$, Munich, Germany) is a trifunctional antibody that binds the epithelial cell adhesion molecule (EpCAM) on tumor cells and CD3 on T lymphocytes. Its intact $\mathrm{Fc}$ region, which is composed of 2 potent immunoglobulin ( $\mathrm{Ig}$ ) isotypes (mouse $\mathrm{IgG}_{2 \mathrm{a}}$ and rat $\mathrm{IgG}_{2 \mathrm{~b}}$ ), binds to type I and III Fcy receptors on accessory cells, including monocytes, macrophages, and dendritic cells [8, 9]. These specificities induce effective tumor cell killing [10, 11], which was recently demonstrated in patients with malignant ascites [12-14].

EpCAM is overexpressed in tumor cells of more than $90 \%$ of patients with GI cancer [15]. Although EpCAM is expressed on normal epithelial tissues, it is specific for tumor cells in the peritoneal cavity because peritoneal cells are of mesothelial origin and therefore do not express EpCAM. In addition, T lymphocytes and accessory cells are present in the peritoneal cavity [16]. Thus, intraperitoneal administration of catumaxomab provides the advantage of targeted immunotherapy for peritoneal tumor cells. Based on this rationale and the convincing results in patients with malignant ascites [12, 13], this study investigated the effects of intraperitoneal catumaxomab therapy in patients with non-ascites-accumulating and non-resectable PC from colon, gastric, or pancreatic cancer.

\section{Patients and Methods}

\section{Patients}

Patients aged $\geq 18$ years with an immunohistochemical diagnosis of EpCAM-positive PC from gastric, colorectal, or pancreatic cancer and with a Karnofsky performance status (KPS) $\geq 60 \%$ were eligible. Exclusion criteria were: prior exposure to mouse monoclonal antibodies or treatment with any investigational drug within the previous 30 days; inadequate organ, immunologic, or endocrine function; uncontrolled acute or chronic infection; chronic steroid therapy; history of severe allergic reaction and ascites $>1000 \mathrm{ml}$ within the previous 30 days. Written informed consent was obtained from all patients. The protocol was approved by independent ethics committees and the study was conducted according to the Declaration of Helsinki and Good Clinical Practice guidelines.

\section{Study Design}

This was an open-label, multicenter, three-part, phase I/II clinical trial to evaluate tolerability and safety, to determine the maximal tolerated dose (MTD) and to obtain preliminary evidence of clinical efficacy for intraperitoneal treatment with catumaxomab in patients with PC. To confirm
EpCAM-positive PC, a tumor sample was collected during laparoscopy or laparotomy 7 days before treatment and analyzed histochemically. A port system was implanted to ensure safe infusions into the peritoneal cavity. Homogenous distribution was controlled by computed tomography (CT) scans after intraperitoneal administration of $2000 \mathrm{ml}$ of balanced electrolyte solution with contrast medium.

Catumaxomab was manufactured by TRION Pharma, Munich, Germany/Fresenius Biotech, Munich, Germany. In part 1 of the study, patients received 4 6-h intraperitoneal infusions of catumaxomab together with $1000 \mathrm{ml}$ electrolyte solution, to ensure homogeneous distribution. A delay of up to 4 days for each infusion was allowed. Premedication consisted of oral acetaminophen $(1000 \mathrm{mg})$. The dose levels for the infusions were composed according to a dynamic escalation schedule as follows - day 0: $10 \mu \mathrm{g}$; day 3: 10 or $20 \mu \mathrm{g}$; day 7: 30, 50, or $100 \mu \mathrm{g}$; and day 10: 50, 100, or $200 \mu \mathrm{g}$, which was based on former studies [12, 17]. Dose escalation was guided by the occurrence of dose-limiting toxicities (DLTs): The MTD was determined separately for the first, second, third, and fourth infusion. If none of 3 patients experienced DLTs, the next dose level for the first, second, third, and fourth infusion was implemented. If one of 3 patients experienced DLTs, a further 3 patients were investigated at that dose level. If none of the additional 3 patients experienced DLTs, subsequent patients received the next highest dose schedule. If 2 or more of 2-6 patients experienced DLTs, the dose-steering board (DSB) defined the MTD. In part 2 of the study, the protocol was amended in order to investigate a shorter administration period of $3 \mathrm{~h}$ at the MTD in another 6 patients. In part 3, patients received 3-h intraperitoneal infusions of catumaxomab at doses higher than the MTD together with dexamethasone $10 \mathrm{mg}$.

\section{Assessments}

Toxicity and vital signs were assessed daily. Human anti-mouse antibody (HAMA) titers were measured to investigate the immunogenicity of catumaxomab. Other immunologic markers included interleukin-6 (IL-6) and tumor necrosis factor-alpha (TNF- $\alpha$ ). PC burden was staged using the classification of Gilly et al. (stages 0-IV; stage I: malignant granulations $<5 \mathrm{~mm}$ in greatest dimension, localized in one part of the abdomen; stage II: malignant granulations $<5 \mathrm{~mm}$, diffuse to the whole abdomen; stage III: malignant granulations $5-2 \mathrm{~cm}$; stage IV: large malignant cakes $(>2 \mathrm{~cm}$ ) [18]. Peritoneal lavages were examined for EpCAM-positive tumor cells using immunohistochemistry at the start and end of treatment. Toxicity was graded using the National Cancer Institute Common Toxicity Criteria (NCI-CTC, version 2.0, 1999). Adverse events were coded using the Medical Dictionary for Regulatory Activities (MedDRA) and tabulated by dose group and time of first appearance, to determine the incidence of adverse events, treatment-related adverse events with a definite, probable, possible, or non-assessable relationship to the study drug, and adverse events of NCI-CTC grade $\geq 3$ or those leading to treatment discontinuation. A DLT was defined as any adverse event grade $\geq 3$ that caused interruption of catumaxomab infusion and could not be relieved by standard therapeutic measures, or any laboratory abnormality grade $\geq 3$ that failed to show a significant trend toward normal within $96 \mathrm{~h}$, or any other condition considered critical to the patient's health. Tumor assessments in patients with measurable disease were made according to the Response Evaluation Criteria in Solid Tumors (RECIST) [19] by CT scans 1 month after the start of treatment. The survival status of patients was assessed every 3 months.

\section{Statistical Analysis}

All study parameters were analyzed descriptively. After the end of the study, a post-hoc, matched-pair analysis was performed to compare the survival of patients with that of a control group of patients who received conventional intravenous chemotherapy. The matched patients were selected from 217 PC patients treated between 2002 and 2005. For matching purposes, only patients with adequate general condition who were able to receive conventional intravenous chemotherapy after diagnosis of PC 
Table 1. Baseline characteristics

\begin{tabular}{|c|c|}
\hline Characteristic & \\
\hline Median age (range), years & $57(26-80)$ \\
\hline & Patients, n (\%) \\
\hline Sex, male/female, n (\%) & $9(38) / 15(62)$ \\
\hline Karnofsky performance status & \\
\hline $70 \%$ & 3 \\
\hline $80 \%$ & 8 \\
\hline $90 \%$ & 11 \\
\hline $100 \%$ & 2 \\
\hline Primary tumor site & \\
\hline Stomach & 10 \\
\hline Colon & 10 \\
\hline Pancreas & 3 \\
\hline Carcinoma of unknown primary & 1 \\
\hline Distant metastasis & 7 \\
\hline Prior surgery & 22 \\
\hline Prior radiotherapy & 3 \\
\hline Prior chemotherapy & 17 \\
\hline $\begin{array}{l}\text { Median time (range) from first diagnosis of } \\
\text { PC, days }\end{array}$ & $79.5(7-347)$ \\
\hline Gilly score $^{\mathrm{b}}$ & \\
\hline Stage I & 1 \\
\hline Stage II & 1 \\
\hline Stage III & 12 \\
\hline Stage IV & 10 \\
\hline
\end{tabular}

$\mathrm{PC}=$ Peritoneal carcinomatosis.

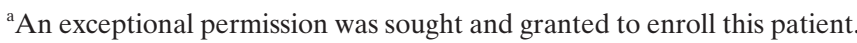
${ }^{b}$ Peritoneal carcinomatosis staging according to Gilly et al. [18]: stage I: malignant granulations $<5 \mathrm{~mm}$ in greatest dimension, localized in one part of the abdomen; stage II: malignant granulations $<5 \mathrm{~mm}$, diffuse to the whole abdomen; stage III: malignant granulations $5-2 \mathrm{~cm}$; stage IV: large malignant cakes $(>2 \mathrm{~cm})$. were considered in order to prevent selection bias favoring PC patients with poor clinical condition and survival. Patients receiving immunotherapy were excluded. Matching variables were primary tumor site and extent of PC according to the classification of Gilly et al. [18]. Sex, age, and incidence of distant metastasis were also considered for matching. Overall survival (OS) was defined as the time from the first diagnosis of PC until death or last follow-up. Kaplan-Meier curves were calculated and the comparison was based on a log-rank test.

\section{Results}

Between 2003 and 2005, 24 patients were enrolled. Most patients were previously treated with surgery and chemotherapy and all but 2 patients had advanced Gilly stage III/IV PC. Mean time from first diagnosis of PC to start of catumaxomab treatment was 113 days (median 79.5, range 7-347 days) (table 1).

\section{Dose Escalation, Schedule Variation, and DLTs}

14 patients were included in part 1, 7 in part 2, and 3 in part 3 (table 2). In parts 1 and 2, the fourth infusion of $200 \mu \mathrm{g}$ was well tolerated and there were no DLTs in any of the 12 patients who received this dose level. Patients treated in part 1 of the study received 46 -h infusions. No DLTs occurred until dose level 4 (table 2). Escalation of the dose level from 50 to $100 \mu \mathrm{g}$ for the third infusion resulted in DLTs in 2 of 3 patients who were scheduled to receive $10-20-100-200 \mu \mathrm{g}$. Patient 01-009 developed grade 3 systemic inflammatory

Table 2. Dose-escalation schedule

\begin{tabular}{|c|c|c|c|c|c|c|c|}
\hline Dose level & Patient no. & Primary tumor site & \multicolumn{4}{|c|}{ Catumaxomab dose $(\mu \mathrm{g})$} & Dose-limiting toxicities (NCI-CTC grade) \\
\hline \multicolumn{8}{|c|}{ Part 1 (6-h infusion) } \\
\hline 1 & $01-001$ & stomach & 10 & $20^{\mathrm{a}}$ & 30 & 50 & - \\
\hline 1 & $01-002$ & colon & 10 & 10 & 30 & 50 & - \\
\hline 2 & $01-004$ & colon & 10 & 20 & 50 & 100 & - \\
\hline 2 & $01-006$ & colon & 10 & 20 & 50 & 100 & - \\
\hline 2 & $01-007$ & colon & 10 & 20 & 50 & 100 & - \\
\hline 3 (MTD) & $01-010$ & stomach & 10 & 20 & 50 & 200 & - \\
\hline 3 (MTD) & $01-013$ & CUP & 10 & 20 & 50 & 200 & - \\
\hline 3 (MTD) & 02-004 & stomach & 10 & 20 & 50 & 200 & - \\
\hline 3 (MTD) & 02-006 & stomach & 10 & 20 & 50 & 200 & - \\
\hline 4 & 01-008 & colon & 10 & 20 & 100 & 200 & - \\
\hline 4 & 01-009 & colon & 10 & 20 & 100 & - & SIRS grade 3 \\
\hline 4 & $02-002$ & colon & 10 & 20 & 84 & - & $\begin{array}{l}\text { dehydration grade } 2 \text {, exfoliative dermatitis grade } 3 \text {, } \\
\text { pyrexia grade } 3 \text {, tachycardia grade } 3 \text {, urticaria grade } 1\end{array}$ \\
\hline \multicolumn{8}{|c|}{ Part 2 (3-h infusion) } \\
\hline 5 & $01-015$ & stomach & 10 & 20 & 50 & 200 & - \\
\hline 5 & 02-008 & stomach & 10 & 20 & 50 & 200 & - \\
\hline 5 & 02-009 & stomach & 10 & 20 & 50 & 200 & - \\
\hline 5 & 02-010 & stomach & 10 & 20 & 50 & - & - \\
\hline 5 & 03-001 & pancreas & 10 & 20 & 50 & 200 & - \\
\hline 5 & $03-003$ & pancreas & 10 & 20 & 50 & 200 & - \\
\hline \multicolumn{8}{|c|}{ Part 3 (3-h infusion + dexamethasone) } \\
\hline 6 & $03-002$ & pancreas & 20 & 50 & 100 & 400 & - \\
\hline 6 & $03-004$ & colon & 20 & 50 & 100 & 400 & - \\
\hline 6 & 03-005 & stomach & 20 & 50 & 100 & - & dyspnea grade 4 \\
\hline
\end{tabular}

CUP = Carcinoma of unknown primary; MTD = maximum tolerated dose; NCI-CTC = National Cancer Institute Common Toxicity Criteria; SIRS = systemic inflammatory response syndrome.

${ }^{\mathrm{a}} \mathrm{A}$ dose of $20 \mu \mathrm{g}$ rather than $10 \mu \mathrm{g}$ was given erroneously. 
response syndrome (SIRS) after the third infusion $(100 \mu \mathrm{g})$. Symptoms included fever $>39.5{ }^{\circ} \mathrm{C}$, skin rash, and impaired liver function (bilirubin $5.6 \mathrm{mg} / \mathrm{dl}$, prothrombin time $60 \%$ ). The patient fully recovered within 1 week. The third infusion was discontinued in patient $02-002$ after $84 \mu \mathrm{g}$ of the planned $100 \mu \mathrm{g}$ had been infused, due to DLTs: fever of $40.2^{\circ} \mathrm{C}$, tachycardia of 164 beats per minute, rash, urticaria, and an increase in liver enzymes. The symptoms responded to treatment with analgesics and antipyretics. The patient recovered within 1 week. Consequently, the MTD was defined by the DSB as dose level 3: 10, 20, 50, and $200 \mu \mathrm{g}$ given on days $0,3,7$, and 10 , respectively.
In part 2 of the study, 7 patients were treated at the MTD, but with a 3-h infusion. No DLTs occurred in this patient group. 1 patient (02-010) did not receive the fourth infusion due to disease-related ascites, but had no DLT. Therefore, a $7^{\text {th }}$ patient was included. In part 3, 2 of 3 patients were treated without any DLTs at dose level $6(20,50,100$, and $400 \mu \mathrm{g})$ using comedication with intravenous dexamethasone. The remaining patient, a woman aged 57 years with PC from gastric cancer and pulmonary metastasis, experienced grade 4 dyspnea $36 \mathrm{~h}$ after the third infusion of $100 \mu \mathrm{g}$ together with fever of $39.0{ }^{\circ} \mathrm{C}$ and transient arterial hypotension. Chest X-ray showed pulmonary edema. Treatment with nasal oxygen,

Table 3. Incidence of treatment-related adverse events by infusion duration in patients treated at the MTD

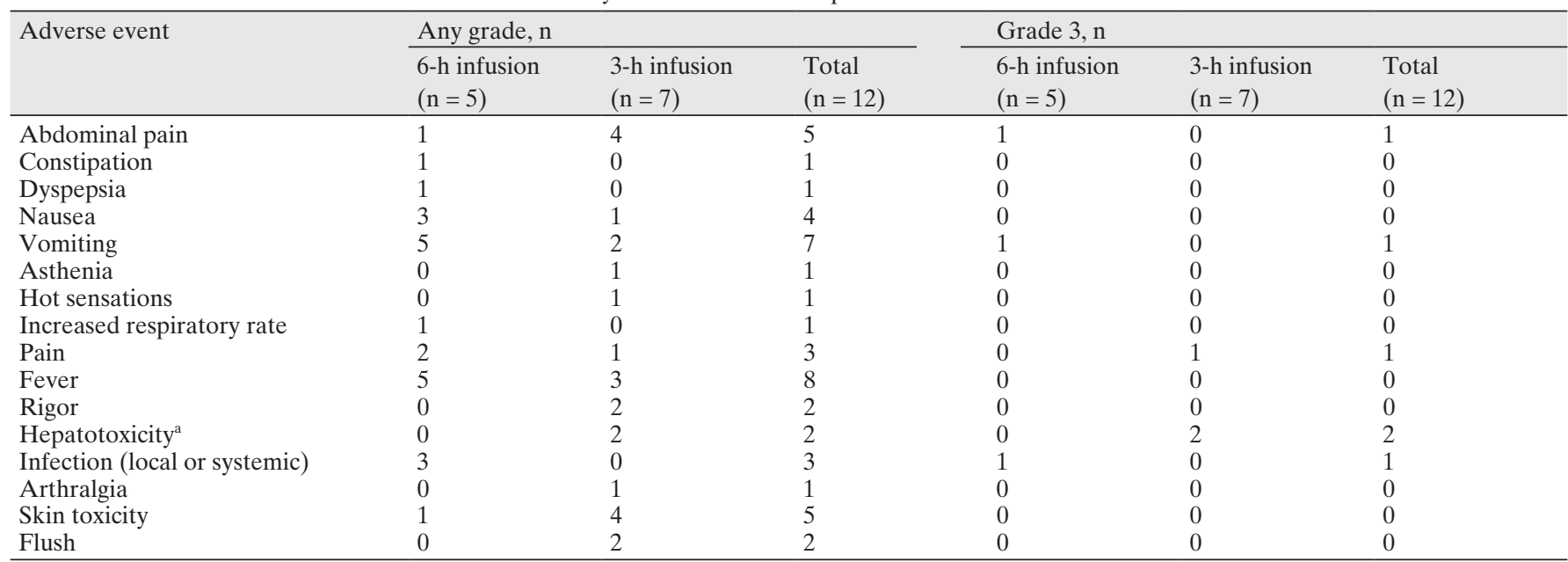

MTD = Maximum tolerated dose.

${ }^{a}$ Including grade 3 alanine aminotransferase and aspartate aminotransferase increases that were classified as a serious adverse event in 1 patient (02-009).

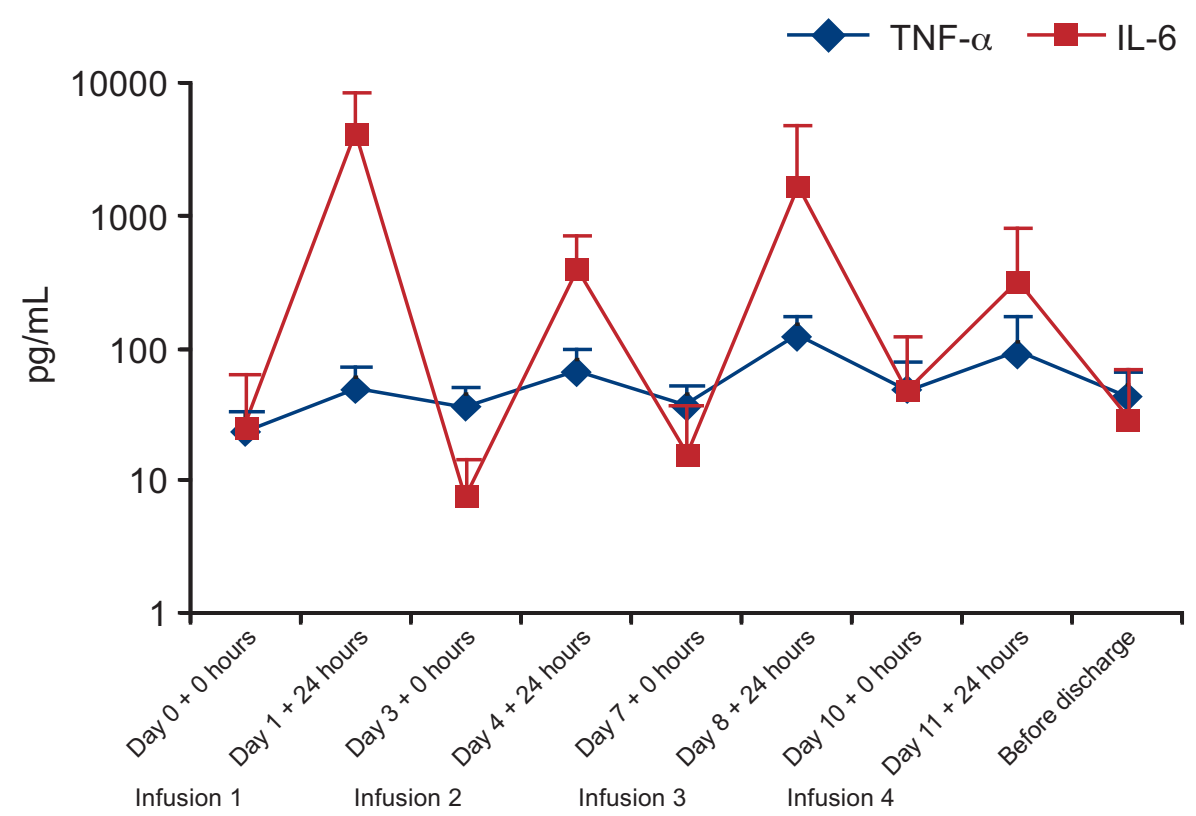

104

Onkologie 2011;34:101-108
Fig. 1. Mean (standard error) cytokine release measured in $\mathrm{pg} / \mathrm{ml}$ for each time point. Each time point on the $\mathrm{x}$-axis shows the day, the infusion number, and the number of hours since the start of the infusion. TNF- $\alpha=$ tumor necrosis factor-alpha; IL-6 = interleukin-6. 
furosemide, dexamethasone, and dimetinden quickly normalized oxygen saturation. General condition and pulmonary function recovered completely. Because of this DLT, no further patients were enrolled.

\section{Safety}

The 12 patients who received catumaxomab at the MTD, either as a 6-h (5 patients) or a 3-h infusion (7 patients), constituted the safety population. A total of 121 adverse events and 95 treatment-related adverse events were reported. Each patient experienced at least 1 treatment-related adverse event. The majority of treatment-related adverse events were mild or moderate; only 13 events affecting 6 patients were NCI-CTC grade 3 . No grade 4 treatment-related adverse events and no drug-related deaths occurred. The most common treatment-related adverse events were fever, vomiting, abdominal pain, skin toxicity, and nausea (table 3 ). Fever was the most common treatment-related adverse event (16 episodes in 8 patients). There was no substantial difference in the incidence of treatment-related adverse events between the 6-h and 3-h infusions. 9 of 12 patients $(75 \%)$ treated at the MTD experienced grade 3 elevations of liver function tests (alanine aminotransferase, aspartate aminotransferase, gamma-glutamyltransferase, alkaline phosphatase, and bilirubin). No significant abnormalities in urinalysis occurred. The overall means of hemoglobin, red blood cell count, and platelet count remained almost constant. The total white cell and neutrophil counts markedly increased while the lymphocyte count transiently decreased after each infusion. Grade 3 lymphopenia developed in 10 patients (83\%). All grade 3 hematologic abnormalities improved to grade $0-2$ at the final examination (about 14 days after the last infusion).

Plasma levels of IL-6 ranged from 1.6 to $134 \mathrm{pg} / \mathrm{ml}$ at baseline and peaked the day after each infusion. The highest IL-6 levels were observed after the first infusion, exceeding the baseline level more than 1000-fold (maximum: 15,308 pg/ml). TNF- $\alpha$ plasma levels varied from $<15$ to $46 \mathrm{pg} / \mathrm{ml}$ at baseline and also increased after the infusions. Peak values were reached after the third and fourth infusion $(>1000 \mathrm{pg} / \mathrm{ml}$ in 3 patients; fig. 1). HAMAs were not detectable in the serum of any patients at the baseline evaluation. Among 11 patients with available data, the HAMA level changed from negative to positive in 7 patients. HAMA titers ranged from $35 \times 10^{6}$ to $520 \times 10^{6} \mathrm{ng} / \mathrm{ml}\left(\right.$ median $\left.71.0 \times 10^{3} \mathrm{ng} / \mathrm{ml}\right)$. There was no clear relationship between elevated HAMA titers and adverse events.

\section{Clinical Efficacy}

17 of 24 patients were evaluable for response according to RECIST criteria. 11 of 17 (65\%) patients were progression free 1 month after the start of treatment. Responses were seen across all dose levels: 1 patient had complete remission, 3 patients had partial remission, and 7 patients had stable disease (table 4). Peritoneal lavage samples at baseline and at

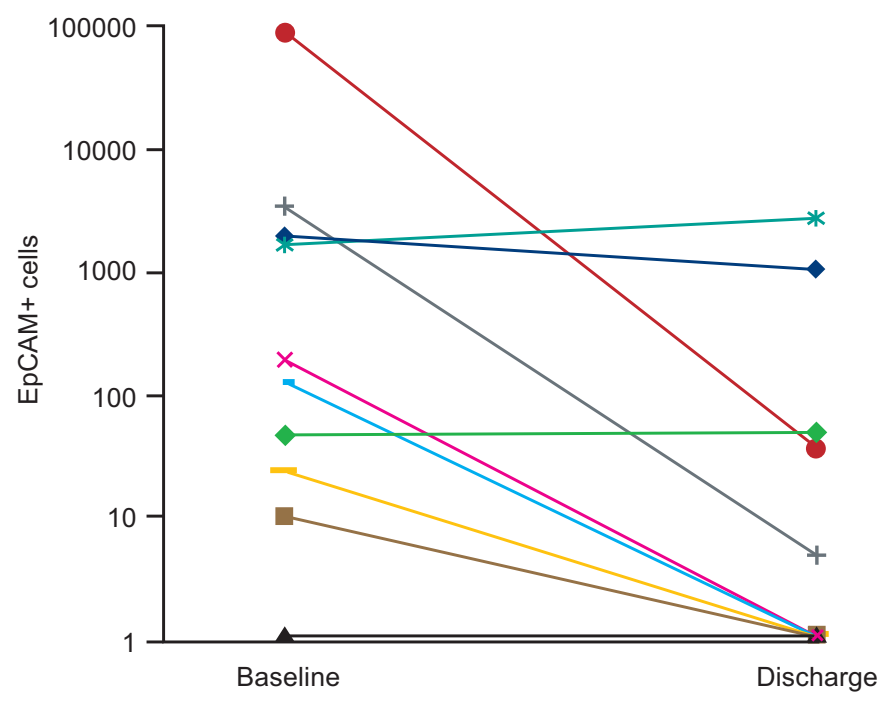

Fig. 2. Individual changes from baseline to discharge in the number of EpCAM-positive cells per $10^{6}$ cells in the peritoneal lavage of 10 patients treated with catumaxomab. Zero values are depicted as 1 on the log scale.

discharge were obtained from 10 patients. No EpCAM-positive tumor cells were detectable at either examination in 1 patient, the number decreased in 6 patients and increased slightly in 3 patients. The most dramatic therapeutic effect was seen in a patient treated at the MTD whose number of EpCAM-positive peritoneal cells decreased from 87,105 to 39 per $10^{6}$ cells (fig. 2 ).

Median OS for all patients (table 4) from the start of treatment was 273 days (9.1 months). Median OS from first diagnosis of PC was 502 days (16.7 months). 10 of 24 patients received chemotherapy after treatment with catumaxomab. Interestingly, no patient had tumor progression in terms of newly diagnosed malignant ascites during follow-up. Since decreasing numbers of EpCAM-positive tumor cells in peritoneal lavages and clinical responses indicated therapeutic efficacy, a matched-pair analysis of OS was performed. The matched control group was identical to the group of study patients in terms of primary tumor site and extent of PC according to the classification of Gilly et al. [18]: The mean Gilly score was 3.3 in both groups. There was no significant difference in age, sex, and incidence of distant metastasis. As required by matching criteria, all patients in the control group received palliative chemotherapy, indicating adequate general condition for antitumor treatment. Median OS in the control group was 180 days (6 months) after first diagnosis of PC. In comparison, patients treated with catumaxomab had a significant survival benefit (log-rank $\mathrm{p}=0.0083)$, with a hazard ratio of 0.421 (95\% confidence interval 0.217-0.817) (fig. 3). 


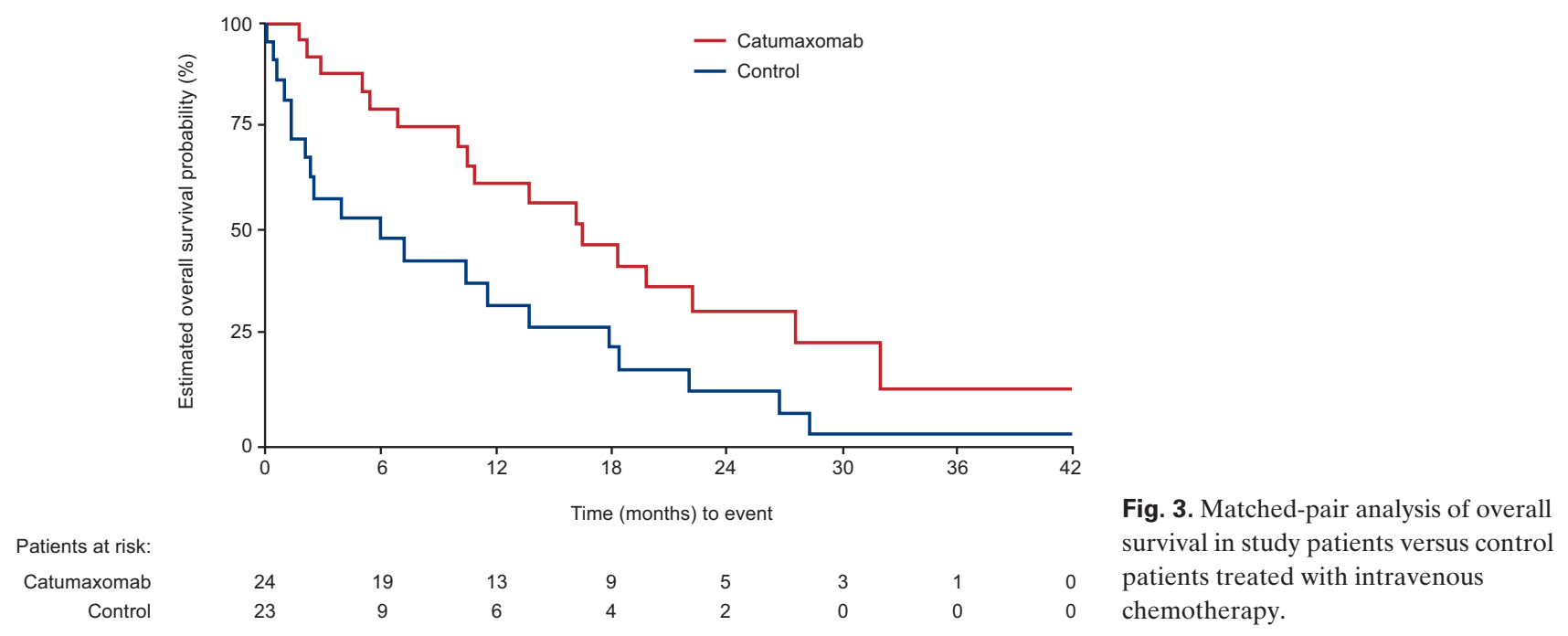

\section{Discussion}

The results of this phase I/II study of the trifunctional antibody catumaxomab demonstrate that PC can be treated safely and effectively with 4 intraperitoneal infusions of catumaxomab. The MTD was reached at doses of 10, 20, 50, and $200 \mu \mathrm{g}$ administered on days $0,3,7$, and 10 , respectively. No patients required treatment in an intensive care unit and no treatment-related deaths occurred. During and after infusions over $3 \mathrm{~h}$, no substantial differences in tolerability were observed. The most common treatment-related adverse events at the MTD were fever, vomiting, abdominal pain, skin toxicity, and nausea. These symptoms are typical of cytokine release and have been observed with several therapeutic antibodies [20, 21]. Measurements of IL- 6 and TNF- $\alpha$ confirmed the findings of a pilot study that these cytokines are released after intraperitoneal infusion of catumaxomab, either as a result of systemic immune activation or a local inflammatory response [12]. However, as cytokine secretion by accessory cells is essential for the antitumor activity of catumaxomab, cytokine release-related symptoms may also reflect immunologic efficacy. Another potential mechanism for causing adverse events is related to the anti-EpCAM-specific binding site. Elevations of liver function tests could be attributed to EpCAM expressed on the epithelium of the small bile ducts [15]. On the other hand, the elevated liver parameters may also be a result of cytokine release [22]. Regarding individual patients, a broad variety of cytokine levels and side effects were seen. There was no observable correlation between individual responses to intraperitoneal catumaxomab and any clinical or immunological parameter before therapy. The adverse-event profile was consistent with that seen during intraperitoneal catumaxomab treatment of patients with malignant ascites $[12,17]$. This point is of special interest as it elucidates the therapeutic options for catumaxomab in the field of PC: In patients with malignant ascites, catumaxomab binding and killing may firstly be directed against floating tumor and im- mune cells in the ascites fluid and secondly against tumor cells on the peritoneal surface. Consequently, patients with malignant ascites could presumably have a different or delayed pattern of adverse events after intraperitoneal therapy. Actually, this study produced the same MTD level without any new adverse events. In summary, intraperitoneal catumaxomab treatment is not limited to malignant ascites but can be performed on patients with PC in an analogous way. This is of special interest as a randomized phase II/III study demonstrated the clinical efficacy of intraperitoneal catumaxomab treatment in patients with malignant ascites, resulting in approval for clinical treatment [14].

Catumaxomab contains xenogeneic protein and thus has the potential for immunogenicity. After therapy, 7 of 11 evaluable patients developed moderate HAMA values, which were not related to the occurrence or severity of adverse events. Generally, the role of HAMA development after antibody therapy remains unclear. High HAMA levels may inhibit antitumor cytotoxicity, but elevated HAMA levels did not inevitably affect successful therapy [23] and were associated with prolonged survival $[24,25]$. In summary, the dose schedule of 10, 20, 50, and $200 \mu \mathrm{g}$ administered on days $0,3,7$, and 10 was regarded as a feasible clinical regimen.

Although clinical efficacy and survival were not primary study endpoints, the results obtained in patients with PC were remarkable. Analysis of EpCAM-positive tumor cells in peritoneal lavages before and after treatment showed a substantial decrease, suggesting peritoneal tumor cell killing. $92 \%$ of all patients in this study had advanced PC (Gilly score of III/ IV), representing poor prognostic features at baseline. In the matched control group, all patients had an adequate general condition to receive intravenous chemotherapy. Therefore, prolonged OS in the catumaxomab group was not caused by a selection bias favoring patients with good prognostic features.

The observation that no study patient developed malignant ascites during follow-up, which could be expected in $20-35 \%$ 
of patients with PC $[5,16]$, indicates that catumaxomab may be clinically effective as a preventive therapy for the development of malignant ascites. No conclusions could be drawn on further dose escalation with dexamethasone premedication due to the low patient numbers. The pilot study of trifunctional antibodies by Heiss et al. [12] included 8 patients with PC and ascites treated with catumaxomab at a maximum total dose of $940 \mu \mathrm{g}$ with intravenous dexamethasone as comedication. This dose schedule was feasible and infusion reactions were manageable. Thus, it is possible that the dose of catumaxomab could be increased safely beyond the MTD when corticosteroids are coadministered.

In conclusion, intraperitoneal treatment with catumaxomab had an acceptable safety profile. It may be a promising option for patients with PC from gastric, colon, or pancreatic cancer. Further trials of catumaxomab, especially in combination with systemic chemotherapy and tumor surgery, are desirable to elucidate its full therapeutic potential in locally advanced GI cancer and PC.

\section{Acknowledgement}

We thank Dr. Anke Klein (Fresenius Biotech $\mathrm{GmbH}$ ) for her critical review of the manuscript.

\section{Disclosure Statement}

The study was sponsored by Fresenius Biotech $\mathrm{GmbH}$, Munich, Germany. Michael Jäger is an employee of TRION Research GmbH. Horst Lindhofer is the inventor and patent holder for catumaxomab and the Chief Executive Officer of TRION Pharma GmbH. Michael Hennig is Head of Biostatistics/Data Management at Fresenius Biotech GmbH. Florian Lordick is a consultant to Fresenius Biotech GmbH. Markus Heiss and Michael Ströhlein are advisors to Fresenius Biotech GmbH and TRION Pharma GmbH. Dominik Rüttinger, KlausUwe Grützner, Oliver C. Schemanski, KarlWalter Jauch, and Christian Peschel declare that they have no competing interests.

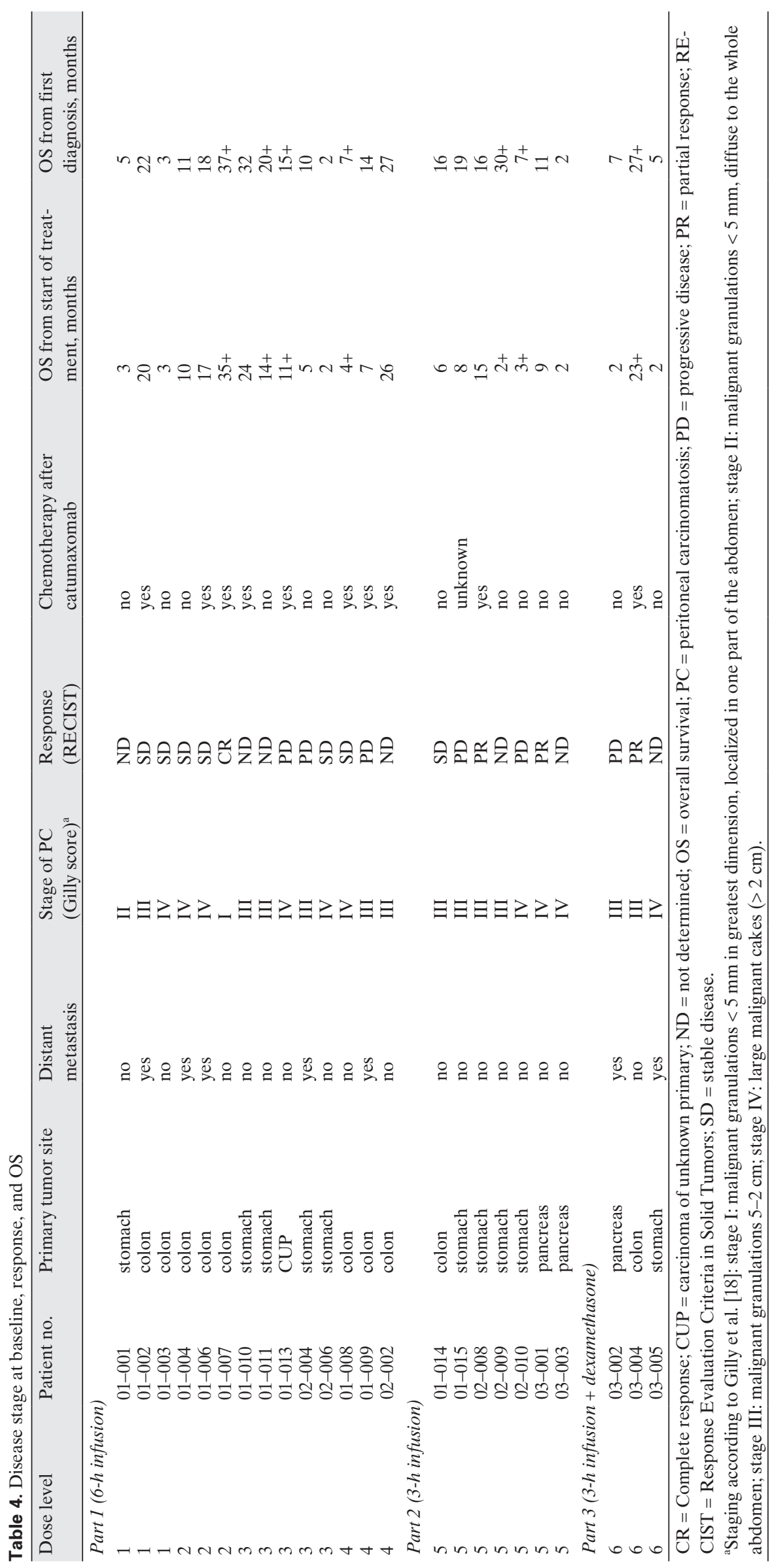

Onkologie 2011;34:101-108 


\section{References}

1 Chu DZ, Lang NP, Thompson C, Osteen PK, Westbrook KC: Peritoneal carcinomatosis in nongynecologic malignancy. A prospective study of prognostic factors. Cancer 1989;63:364-367.

2 Preusser P, Wilke H, Achterrath W, Fink U, Lenaz L, Heinicke A, Meyer J, Meyer HJ, Buente H Phase II study with the combination etoposide, doxorubicin, and cisplatin in advanced measurable gastric cancer. J Clin Oncol 1989;7:1310-1317.

3 Ajani JA, Ota DM, Jessup JM, Ames FC, McBride C, Boddie A, Levin B, Jackson DE, Roh M, Hohn D: Resectable gastric carcinoma. An evaluation of preoperative and postoperative chemotherapy. Cancer 1991;68:1501-1506.

4 Jayne DG, Fook S, Loi C, Seow-Choen F: Peritoneal carcinomatosis from colorectal cancer. $\mathrm{Br} \mathrm{J}$ Surg 2002;89:1545-1550.

5 Sadeghi B, Arvieux C, Glehen O, Beaujard AC, Rivoire M, Baulieux J, Fontaumard E, Brachet A, Caillot JL, Faure JL, Porcheron J, Peix JL, François Y, Vignal J, Gilly FN: Peritoneal carcinomatosis from non-gynecologic malignancies: results of the EVOCAPE 1 multicentric prospective study. Cancer 2000;88:358-363.

6 Sugarbaker PH, Chang D: Results of treatment of 385 patients with peritoneal surface spread of appendiceal malignancy. Ann Surg Oncol 1999;6:727731

7 Verwaal VJ, van Ruth S, de Bree E, van Sloothen GW, van Tinteren H, Boot H, Zoetmulder FA Randomized trial of cytoreduction and hyperthermic intraperitoneal chemotherapy versus systemic chemotherapy and palliative surgery in patients with peritoneal carcinomatosis of colorectal cancer. J Clin Oncol 2003;21:3737-3743.

8 Zeidler R, Reisbach G, Wollenberg B, Lang S, Chaubal S, Schmitt B, Lindhofer H: Simultaneous activation of $T$ cells and accessory cells by a new class of intact bispecific antibody results in efficient tumor cell killing. J Immunol 1999;163:1246-1252.

9 Zeidler R, Mysliwietz J, Csánady M, Walz A, Ziegler I, Schmitt B, Wollenberg B, Lindhofer H: The Fc-region of a new class of intact bispecific antibody mediates activation of accessory cells and NK cells and induces direct phagocytosis of tumour cells. Br J Cancer 2000;83:261-266.

10 Riesenberg R, Buchner A, Pohla H, Lindhofer H Lysis of prostate carcinoma cells by trifunctional bispecific antibodies (alpha EpCAM $\times$ alpha CD3). J Histochem Cytochem 2001;49:911-917.
11 Ruf P, Lindhofer H: Induction of a long-lasting antitumor immunity by a trifunctional bispecific antibody. Blood 2001;98:2526-2534.

12 Heiss MM, Ströhlein MA, Jäger M, Kimmig R, Burges A, Schoberth A, Jauch KW, Schildberg FW, Lindhofer H: Immunotherapy of malignant ascites with trifunctional antibodies. Int J Cancer 2005; 117:435-443.

13 Heiss MM, Murawa P, Koralewski P, Kutarska E, Kolesnik OO, Ivanchenko VV, Dudnichenko AS, Aleknaviciene B, Razbadauskas A, Gore M, Ganea-Motan E, Ciuleanu T, Wimberger P, Schmittel A, Schmalfeldt B, Burges A, Bokemeyer C, Lindhofer H, Lahr A, Parsons SL: The trifunctional antibody catumaxomab for the treatment of malignant ascites due to epithelial cancer: Results of a prospective randomized phase II/III trial. Int J Cancer 2010;127:2209-2221.

14 Seimetz D, Lindhofer H, Bokemeyer C: Development and approval of the trifunctional antibody catumaxomab (anti-EpCAM $\times$ anti-CD3) as a targeted cancer immunotherapy. Cancer Treat Rev 2010;36:458-467.

15 Went P, Vasei M, Bubendorf L, Terracciano L, Tornillo L, Riede U, Kononen J, Simon R, Sauter G, Baeuerle PA: Frequent high-level expression of the immunotherapeutic target Ep-CAM in colon, stomach, prostate and lung cancers. Br J Cancer 2006;94:128-135.

16 Parsons SL, Lang MW, Steele RJ: Malignant ascites: a 2-year review from a teaching hospital. Eur J Surg Oncol 1996;22:237-239.

17 Burges A, Wimberger P, Kümper C, Gorbounova V, Sommer H, Schmalfeldt B, Pfisterer J, Lichinitser M, Makhson A, Moiseyenko V, Lahr A, Schulze E, Jäger M, Ströhlein MA, Heiss MM, Gottwald T, Lindhofer H, Kimmig R: Effective relief of malignant ascites in patients with advanced ovarian cancer by a trifunctional anti-EpCAM $\times$ anti-CD3 antibody: a phase I/II study. Clin Cancer Res 2007;13:3899-3905.

18 Gilly FN, Carry PY, Sayag AC, Brachet A, Panteix G, Salle B, Bienvenu J, Burgard G, Guibert B, Banssillon V, Braillon G: Regional chemotherapy (with mitomycin C) and intra-operative hyperthermia for digestive cancers with peritoneal carcinomatosis. Hepatogastroenterology 1994;41:124129.
19 Therasse P, Arbuck SG, Eisenhauer EA, Wanders J, Kaplan RS, Rubinstein L, Verweij J, Van Glabbeke M, van Oosterom AT, Christian MC, Gwyther SG: New guidelines to evaluate the response to treatment in solid tumors. European Organization for Research and Treatment of Cancer, National Cancer Institute of the United States, National Cancer Institute of Canada. J Natl Cancer Inst 2000;92:205-216.

20 Lewis LD, Cole BF, Wallace PK, Fisher JL, Waugh M, Guyre PM, Fanger MW, Curnow RT, Kaufman PA, Ernstoff MS: Pharmacokinetic-pharmacodynamic relationships of the bispecific antibody MDX-H210 when administered in combination with interferon gamma: a multiple-dose phase-I study in patients with advanced cancer which overexpresses HER-2/neu. J Immunol Methods 2001;248:149-165.

21 Winkler U, Jensen M, Manzke O, Schulz H, Diehl $\mathrm{V}$, Engert A: Cytokine-release syndrome in patients with B-cell chronic lymphocytic leukemia and high lymphocyte counts after treatment with an anti-CD20 monoclonal antibody (rituximab, IDEC-C2B8). Blood 1999;94:2217-2224.

22 Prandota J: Important role of proinflammatory cytokines/other endogenous substances in druginduced hepatotoxicity: depression of drug metabolism during infections/inflammation states, and genetic polymorphisms of drug-metabolizing enzymes/cytokines may markedly contribute to this pathology. Am J Ther 2005;12:254-261.

23 Marmé A, Strauss G, Bastert G, Grischke EM, Moldenhauer G: Intraperitoneal bispecific antibody (HEA125xOKT3) therapy inhibits malignant ascites production in advanced ovarian carcinoma. Int J Cancer 2002;101:183-189.

24 DeNardo GL, Bradt BM, Mirick GR, DeNardo SJ Human antiglobulin response to foreign antibodies: therapeutic benefit? Cancer Immunol Immunother 2003;52:309-316.

25 Ott MG, Lindhofer H, Linke RG, Hennig M, Martinius H, Klein A, Seimetz D: The trifunctional antibody catumaxomab: Correlation between immunological response and clinical outcome - new analysis of a pivotal phase II/III study. J Clin Oncol 2010;28(suppl 15):abstr 2551. 